LIAMES 4 - pp. 169-180, Primavera 2004

Adriana M.S. Viana

(Mestr. UnB)

\title{
Tempo, aspecto e modo em Boróro
}

\section{RESUMO}

Este trabalho inicia uma discussão sobre a análise dos morfemas que expressam tempo, aspecto e modo na língua Boróro, tratados como sufixos por Crowell (1979). Apresentamos algumas evidências que questionam essa análise e levam a uma outra perspectiva, que considera esses elementos não como sufixos, mas como clíticos. O principal argumento em favor dessa análise é o fato de esses elementos não selecionarem de maneira rígida as categorias gramaticais às quais se ligam, podendo estar ligados a nomes, a verbos, a pronomes e ao que Crowell chama de adjetivos. Outro argumento é o fato de a relação que tais elementos estabelecem com as raízes a que se ligam ser de natureza mais sintática que morfológica.

PALAVRAS-CHAVE Boróro; Tempo; Aspecto; Modo; Clíticos.

\section{RESUMEN}

Ese trabajo inicia una discusión acerca del análisis de los morfemas responsables por la expresión de tiempo, aspecto y modo en la lengua Boróro (familia Boróro, tronco lingüístico Macro-Jê), tratados como sufijos por Crowell (1979). Presentamos algunas evidencias que cuestionan aquel análisis y llevan a otra perspectiva, que considera esos elementos no como sufijos, sino como formas dependientes (clíticos). El principal argumento a favor de este análisis es el hecho de que esos elementos no seleccionan de manera rígida las categorías gramaticales a las cuales se ligan, de manera que pueden ligarse a nombres, a verbos, a pronombres y a lo que Crowell denomina adjetivos. Otro argumento a favor de este análisis es el hecho de que, la relación que tales elementos establecen con las raíces a que se ligan, es de naturaleza más sintáctica que morfológica.

Palabras llave Boróro; Tiempo; Aspecto; Modo; Cliticos.

\section{INTRODUÇÃO}

O objeto de estudo deste trabalho são os morfemas que expressam tempo, aspecto e modo na língua Boróro - língua indígena brasileira falada pelos índios de igual denominação, pertencente ao tronco lingüístico Macro-jê e à família Boróro (cf.: Rodrigues, 1986). 
Análises tradicionais da língua (cf.: Crowell, 1979) consideram esses morfemas como sufixos, fato que estaremos investigando mais cuidadosamente neste trabalho, já que tais elementos apresentam comportamentos bem diferenciados do que se espera de verdadeiros afixos.

Mais especificamente, estaremos explorando a hipótese de que os morfemas que expressam tempo, aspecto e modo em Boróro são, na verdade, clíticos e não sufixos.

Os dados analisados foram os mesmos já estudados por Colbacchini \& Albisetti (1942) e Crowell (1979) e, eventualemente, os contidos na Enciclopédia Boróro, de Albisetti \& Venturelli (1976), volume III, em Rondon \& Faria (1948), Huestis (1968) e Tonelli (1926) in Colbacchini \& Albisetti (1942).

No que se refere à análise fonológica, estaremos adotando, em princípio, Crowell (1977), Rondon \& Faria (1948) e considerando o trabalho de Rodrigues (1962) (apud, Schultz, 1962) em que ele compara alguns dados do Boróro com dados do Umutína - língua também pertencente à família Boróro.

Para a descrição e a análise de dados, neste trabalho, adotamos a abordagem tipológicofuncional, especialmente a apresentada por Shopen (1985).

\section{OPROBLEMA E OS CAMINHOS}

Segundo Crowell (1979: 86), o Boróro possui dez traços que carregam informações de tempo, aspecto e modo. Normalmente, não é possível, segundo o autor, distinguir claramente o que indica o modo, o que indica o tempo e o que indica o aspecto. Por essa razão, ele passa a se referir a esses elementos como simplesmente traços de aspecto ${ }^{1}$. De acordo com o autor, as orações do Boróro dividem-se em dependentes e independentes. As independentes podem ser, quanto ao aspecto (no sentido de Crowell) imperativas, exortativas, declarativas ou interrogativas, ao passo que as dependentes podem ser finais (expressando finalidade), finitas e não-finitas. As orações dependentes finitas, segundo o autor, apresentam um esquema aspectual igual ao das orações declarativas independentes; as não-finitas não selecionam nenhum aspecto e as finais apresentam a posposição bogai para desempenhar o papel do aspecto.

\footnotetext{
${ }^{1}$ Chamaremos esses elementos de morfemas de tempo, aspecto e modo, ou, simplesmente, de morfemas TAM.
} 
Quadro 1: Esquema aspectual do Boróro proposto por Crowell (1979)

\begin{tabular}{|c|c|c|c|}
\hline \multicolumn{2}{|c|}{ Orações Independentes } & \multicolumn{2}{|c|}{ Orações Dependentes } \\
\hline Aspecto & Morfema & Aspecto & Morfema \\
\hline $\begin{array}{l}\text { 1. Imperativo } \\
\text { 2. Exortativo } \\
\text { 3. Declarativo } \\
\text { • Recente } \\
\text { - Não-recente } \\
\text { - Neutro } \\
\text { - Hipotético } \\
\text { - Estativo } \\
\text { - Iterativo } \\
\text { 4. Interrogativo sim/não } \\
\text { 5. Interrogativo -wh }\end{array}$ & $\begin{array}{l}\text {-ba } \\
\text {-wëe } \\
-\varnothing \\
-\mathbf{r a u} / \mathbf{r u} \\
\text { re }^{2} \\
- \text {-mëdi }^{3} \\
\text {-nire } \\
\text { duplicação da raiz }_{\text {entonação }} \\
\text {-ba }\end{array}$ & $\begin{array}{l}\text { 1. Finalidade } \\
\text { 2. Não-finito } \\
\text { 3. Finito }\end{array}$ & $\begin{array}{l}\text { Posposição bogai } \\
\text { Não seleciona aspecto } \\
\text { Segue o esquema das } \\
\text { declarativas } \\
\text { independetes }\end{array}$ \\
\hline
\end{tabular}

No quadro acima, apresentamos uma síntese do esquema aspectual das orações do Boróro proposto por Crowell.

Abaixo apresentamos um exemplo de cada uma das possibilidades dadas no quadro acima, de acordo com Crowell (1979). Em (1), temos uma oração imperativa; em (2), uma exortativa; em (3) uma no passado recente; em (4) uma que apresenta o não-recente e o estativo simultaneamente; em (5) uma no aspecto neutro; em (6) uma que apresenta, simultaneamente, o hipotético e o neutro; em (7) uma oração iterativa; em (8) uma interrogativa e, finalmente, em (9), uma que expressa finalidade.

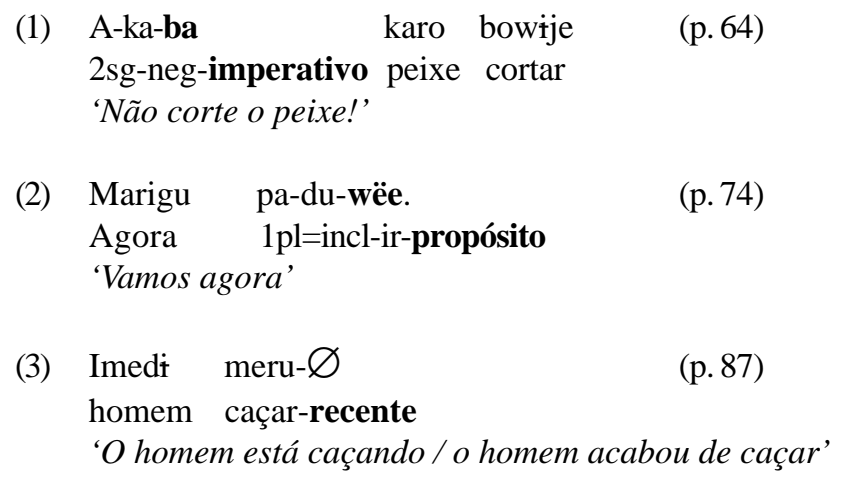

\footnotetext{
${ }^{2}$ De acordo com Crowell, quando nem o imperativo nem o recente são selecionados, o sistema oferece uma escolha entre o neutro e o estativo. Segundo o autor, a grande maioria das orações do Boróro seleciona o aspecto neutro, que pode vir acompanhado do hipotético. Ele observa ainda que quando o neutro é selecionado, mas não o hipotético, a oração tem uma interpretação de presente ou de passado, com a distinção entre os dois feita pelo sentido do contexto ou por sintagmas temporais.

Se preceder o neutro -re, tem-se mëde.
} 
172

(4) E-mago-ru-nire

3pl-falar-incerteza-estativo

'Eles podem estar falando'

(5) Imedi maragori-re

homem trabalhar-neutro

'O homem está trabalhando / trabalhou'

(6) U-tu-mëde

3sg-ir-hipotético+neutro

'Ele provavelmente irá'

(7) I-tu-i-tu-re toro [...]

1sg-ir-1sg-ir-neutro lá

(p. 102)

'Eu repetidamente ia lá [...]'

(8) Kai-ba kodu-re?

Onde ir-neutro

(p. 77)

'Onde ele foi?'

(9) Maragodit-re dinheiro-bogai (p. 107)

Trabalhar-neutro dinehiro-por

'Ele trabalhou por dinehiro'

Crowell (op. cit.) ainda afirma que traços de aspecto (TAM) são realizados, em Boróro, como sufixos (p. 86) e ocorrem seguindo os sujeitos agentivos em orações transitivas que possuem agentes e seguindo os verbos em orações que não possuem agentes (p. 24). O lugar do aspecto é, então, determinado em função de o traço agentivo ser ou não selecionado: se o agentivo é selecionado, o aspecto segue o sujeito agentivo; se o agentivo não é selecionado, o aspecto segue o verbo (p. 24).

Contudo, o autor não apresenta uma definição formal de sujeito agentivo e de sujeito não-agentivo e os dados que apresenta são controversos.

Em (10), abaixo, apresentamos um exemplo de oração em que o aspecto neutro -re segue o que Crowell considera como sujeito. Portanto, segundo a sua previsão, trata-se de uma oração transitiva agentiva, com o que, em princípio, concordamos.

(10) Ime e-re areme e-wiie ${ }^{4} \quad$ (p.22)

homem 3pl-neutro mulher 3pl-aconselhar

'Os homens aconselharam as mulheres'

4 Apesar de o autor ter fornecido a glosa referente a esse dado, há uma questão não esclarecida: por que o elemento referente ao sujeito e (ou, em outra interpretação, o próprio sujeito) aparece duas vezes na oração? Essa é uma questão que não poderemos discutir no âmbito deste trabalho, mas que deverá ser retomada em trabalhos posteriores. 
Já em (11), apresentamos um exemplo de uma oração em que o aspecto neutro -re segue o verbo, o que, segundo a previsão de Crowell, deveria ser uma oração não-agentiva, o que não parece $\operatorname{ser}^{5}$.

\section{(11) E-meru-re}

3pl-caçar-neutro

'Eles caçaram'

Crowell ainda observa que orações copulativas (equativas, existenciais e identificacionais) não contém verbo, apenas NPe Asp. Em (12), abaixo, apresentamos um exemplo de oração existencial.

(12) Pëbë-re wëë água-neutro aqui

'Tem água aqui'

Contudo, os dados apresentados em (10), (11) e (12), assim como a própria observação de Crowell quanto à posição dos morfemas aspectuais na oração se mostram problemáticos para uma análise mais rígida desses elementos como sufixos.

Nas seções 2.1, 2.2 e 2.3., a seguir, passaremos a discutir os principais problemas envolvidos nessa análise.

\subsection{Não-seleção dos morfemas TAM com relação às raízes a que se ligam}

A literatura lingüística tende a considerar que os afixos, de maneira geral, apresentam um alto grau de seleção com relação às raízes a que se ligam (cf.: Anderson, 1985; Schachter, 1985; Zwicky \& Pullun, 1993; Zwicky, 1977 e Zwicky, 1985). Isso pode ser observado em muitos paradigmas de muitas línguas. Em português, por exemplo, o sufixo -mos, indicativo de $1^{\text {a }}$ pessoa do plural só pode ocorrer com verbos, ao passo que um sufixo como -s, indicativo de plural, só pode ocorrer com categorias nominais, como adjetivo e substantivo, por exemplo.

Diferentemente, não parece haver, de maneira geral, uma restrição categorial no que se refere à relação clítico-hospedeiro.

Em Boróro, o que observamos é que os morfemas TAM não selecionam categorialmente as raízes a que se ligam. Eles podem estar ligados a verbos, como em (13), a nomes, como em (14) a partículas indicativas de sujeito, como em (15) e a elementos que Crowell classifica como adjetvos, como em (16) :

5

Na página 21, Crowell afirma que todas as orações do Boróro apresentam a ordem NP V Asp, com exceção das orações transitivas agentivas. Isso nos leva a crer que, além das transitivas não-agentivas, as intransitivas também apresentam a ordem $\mathrm{V}$ asp.

${ }_{7}^{6}$ A categorização dessas partículas será discutida mais adiante.

Na verdade, não parece muito possível que esses elementos sejam, de fato, adjetivos. Contudo, deixaremos essa discussão para uma próxima oportunidade. 
174

(13) E-mago-re tori-ji
3pl-falar-neutro montanha-referente
'Eles falaram sobre as montanhas'

(p. 29)

(14) Kare-re

(p. 37)

peixe-neutro

'Tem peixe'

(15) E-re karo kowïje

3pl-neutro peixe comer

'Eles comeram o peixe'

(16) I-kuri-re

(p. 26)

1sg-grande-neutro

'Eu sou grande'

Dados como os apresentados acima mostram claramente que não há nenhum tipo de seleção por parte dos morfemas que expressam tempo, aspecto e modo do Boróro em relação às raízes a que se ligam e que a sua ligação com o elemento precedente é de outra natureza — que estaremos discutindo na próxima seção.

Essa característica observada nesses morfemas não são típicas de sufixos. Pelo contrário: a seleção categorial feita pelos afixos de maneira geral em relação às raízes às quais se anexam é muito forte e não parece poder ser quebrada.

Por outro lado, essa não seletividade observada nos morfemas que expressam tempo, aspecto e modo em Boróro é um traço característico dos clíticos. Conforme já apontamos, os clíticos apresentam um baixo grau de seleção com relação aos seus hospedeiros.

Esse é, então, o argumento mais forte em favor de uma análise dos morfemas que expressam tempo, aspecto e modo do Boróro como clíticos e não como sufixos.

\subsection{A posição dos morfemas TAM na oração}

Outra questão que se coloca contra a análise dos morfemas TAM do Boróro como sufixos é o fato de eles terem uma posição relativamente fixa no âmbito da oração e não no interior das palavras: numa oração transitiva agentiva, esses morfemas seguem o sujeito agente; nos outros casos, seguem o verbo.

A colocação desses morfemas na oração é algo que parece se relacionar mais com a sintaxe da oração do que com a morfologia interna das palavras, já que, por um lado, são restrições sintáticas que determinam a sua alocação na oração e, por outro, não se pode afirmar que tais elementos sejam partes constitutivas de palavras.

Dessa forma, não podem, então, ser consideradas como sufixos. Os sufixos, como podemos constatar na literatura lingüística, são elementos que constituem palavras, sendo, obrigatoriamente, parte delas, não podendo, portanto, ser separados delas e que, também por isso, selecionam rigidamente a categoria das palavras às quais podem se ligar. 
Apesar de chamar esses elementos de sufixos, a hipótese de Crowell a respeito da posição em que esses morfemas aparecem na oração é interessante e deverá ser mais explorada futuramente.

De qualquer forma, o que importa nesse momento é colocarmos em evidência o fato de esses elementos manterem uma relação mais sintática que morfológica as raízes a que se ligam, característica que os afasta dos sufixos e os aproxima dos clíticos.

\subsection{Sufixos de Prefixos?}

Outra questão que se coloca contra a análise de Crowell é o fato de, por um lado, ele considerar os morfemas aspectuais do Boróro como sufixos e, por outro, os morfemas indicativos de sujeito, de prefixos ${ }^{8}$. Segundo ele, os verbos, as posposições e os nomes inalienavelmente possuíveis são, obrigatoriamente flexionados para pessoa e número por meio de prefixos (cf.: Crowell, 1977: 159) ${ }^{9}$.

Bem, se é verdade que os morfemas aspectuais são sufixos, eles devem, obrigatoriamente, estar ligados a uma raíz. Da mesma forma, se as morfemas flexionais indicativos de sujeito são prefixos, eles também devem estar ligados a uma raiz. No entanto, o que observamos em dados como (10) e (15), acima, e (17) e (18), abaixo, é o fato de os sufixos aspectuais estarem ligados a prefixos pessoais, sem raiz nenhuma envolvida no processo:

(17) E-re karo boeije

3pl-neutro peixe cortar

'Eles cortaram o peixe'

(18) I-re bola doge e-warigu 1sg-neutro bola plural 3pl-atirar

'Eu atirei as bolas'

Este é outro problema para a análise de Crowell, que pode ser resolvida de quatro formas:

(a) considerarmos os morfemas TAM como palavras independentes e os morfemas pessoais como prefixos;

(b) considerarmos os morfemas TAM como palavras independentes e os morfemas pessoais como clíticos;

(c) considerarmos os morfemas TAM como sufixos e os morfemas pessoais como palavras independentes e

(d) considerarmos os morfemas TAM como clíticos e os morfemas pessoais como palavras independentes.

\footnotetext{
${ }^{8}$ O problema que se coloca para a análise de Crowell nesse ponto não se refere especialmente aos morfemas TAM, mas aos elementos a que o autor classifica como prefixos. Contudo, como a análise de um elemento interfere na análise dou outro, estamos trazendo essa questão para este trabalho.

A pessoa de que trata Crowell refere-se, quase sempre, ao sujeito.
} 
Passemos, agora, a analisar cada uma das possibilidades acima.

A alternativa (a) se mostra inadequada porque não foi encontrada, nos dados analisados, nenhuma ocorrência livre de morfemas TAM. Eles sempre ocorrem ligados a algum elemento e esse seria, então, um indicativo — que deverá ser testado com maior rigor — de que tais elementos não são palavras independetes.

Outro problema que se coloca para essa análise refere-se ao status dos morfemas pessoais. De acordo com a literatura lingüística, uma das características dos sufixos é o fato de eles não terem acento próprio, o que não se pode afirmar para esses elementos, pelo menos de acordo com Colbacchini \& Albisetti (1942).

Esses autores, discutindo fonologicamente raízes verbais monossilábicas, afirmam que o verbo tu, por exemplo, torna-se enclítico ao pronome pessoal u 'ele', produzindo a forma ú-ttu 'ele vai'.

É importante salientar que, tanto na obra de Colbachini \& Albisetti quanto na obra de Crowell, há uma confusão muito grande na análise desses morfemas pessoais. Tanto um quanto outro trabalho se referem a esses elementos ora como prefixos, ora como pronomes. Contudo, um dado apresentado por Colcachini \& Albisetti parece desfazer a confusão. Em (19), abaixo, retirado de Colbachini \& Albisetti, encontramos a ocorrência livre do morfema pessoal I:

$\begin{array}{lll}\text { (19) I } & \text { moddukare } & \text { bitto }^{10} \\ \text { eu } & \text { (negação) } & \text { matar } \\ \text { 'Eu não matarei' } & \end{array}$

Ora, se o morfema I fosse um verdadeiro prefixo, jamais poderia ser separado da raíz a ele ligada, como ocorre em (19). No dado acima, temos uma espécie de sintagma advrrbiala palavra modukkare - entre o morfema pessoal I e o verbo bitto. Essa é, ao nosso ver, a prova cabal de que os morfemas que expressam pessoa, em Boróro, não são sufixos, mas palavras independentes. Mais especificamente, estamos defendendo, em princípio, que essas palavras pertencem à classe dos pronomes.

Mesmo assim, com a evidência desse dado, os autores não admitem se tratar de pronomes e dizem: "[...] muitas vezes, porém, entre o verbo e os prefixos, podem existir substantivos, advérbios, partículas negativas, etc.". Ora, se se tratasse mesmo de um prefixo, não seria possível a inserção de uma palavra entre ele e a raiz a ele ligada.

Rodrigues (2000: 230), demonstra compartilhar também dessa análise ao afirmar que "pronomes presos" têm status de palavras pronominais (formas livres), já que podem servir de base para os marcadores de aspecto e negação:
(20) $a=$ mëdi $=k a=r e$
bai poro
$\mathrm{mi}$
2.sg=HIPOT=NEG=NEUTRO casa buraco fechar
'Você não deveria fechar a porta'

${ }^{10}$ A glosa não foi fornecida pelos autores. 
Igualmente inadequada se mostra também a alternativa (b). Por um lado, pelos motivos já descritos acima, não temos elementos suficientes para considerarmos os morfemas TAM como palavras independentes. Por outro, depois de constatar a possibilidade de os morfemas pessoais poderem ocorrer livremente e de serem acentuados, não seria plausível os tratarmos como clíticos, cujas características são incompatíveis com as apresentadas por esses elementos.

A alternativa (c) é melhor do que a (a) e a (b) porque considera a possibilidade de os morfemas pessoais serem palavras independentes, mas falha ao propor que os morfemas aspectuais sejam sufixos. Como já vimos na seção 2.1, uma das principais características dos sufixos é a rígida seleção que fazem em relação às raízes a que se ligam, o que não ocorre nesse caso.

Resta-nos, então, a alternativa (d), que considera os morfemas pessoais como palavras independentes - o que parece razoável, se considerarmos o dado (19) — e os morfemas aspectuais como clíticos, única análise possível no momento, diante do quadro que temos.

Falta, contudo, à nossa análise, o teste acentual. Para termos certeza de que esses elementos são clíticos e não palavras independentes, temos de estar certos de que eles não possuem acento próprio, tendo, então, de se apoiarem em palavras, inerentemente acentuadas: os hospedeiros. Contudo, esse teste não poderá ser realizado até que tenhamos a possibilidade de buscar essa informação com falantes nativos da língua, já que os trabalhos que tratam da fonologia do Boróro (Crowell, 1977), Rondon (1948), Colbalcchini \& Albisetti e Rodrigues (1962) não tocam nessa questão. Esse teste é crucial e é também o mais importante para a nossa análise: se ficar comprovado que esses elementos possuem acento próprio, deverão ser analisados como palavras independentes; se, por outro lado, comprovarmos que tais morfemas são desprovidos dessa propriedade, fica, então, comprovada a nossa hipótese inicial de que esses elementos são clíticos.

Voltando à questão dos morfemas pessoais, é importante salientar ainda que Colbacchini \& Albisetti (1942) em certo ponto de sua obra, referem-se a esses elementos como pronomes, e afirmam que eles podem ocorrer independentemente (pronomes absolutos) ou precedidos pelos verbos (sufixos).

Huestis (1968) também compartilha também com essa análise,dividindo os pronomes em pronomes ligados e sintagmas pronominais-nominais apositivos.

Sobre essa questão, Rondon \& Faria (1948) sugerem que as chamadas formas presas são, na verdade, formas reduzidas das chamadas formas livres. A esse respeito, afirmam que "a não ser em casos especiais, os pronomes pessoais são empregados sempre sob a forma abreviada ${ }^{11}$ :

${ }^{11}$ Os autores não explicam que casos especiais seriam esses. 
178

$$
\begin{aligned}
& i \quad \text { - em vez de- imi } \\
& a \quad \text {-em vezde- áqui }{ }^{12} \\
& \text { u -em vezde- áuo } \\
& \text { pa —emvezde- págui } \\
& \text { xê —em vez de- xêgui } \\
& \text { ta -emvezde- tágui } \\
& \text { é - emvezde- émague" }
\end{aligned}
$$

\section{AORDEMDOS MORFEMASASPECTUAIS NOSINTAGMA}

Quanto à ordem de realização dos traços de tempo, aspecto e modo em Boróro, Crowell observa que o traço de incerteza acrescido do traço estativo ou neutro podem ser selecionados na mesma oração. Se o neutro é selecionado, o hipotético também pode ser e, nesse caso, a ordem de realização dos traços é incerteza-estativo ou incertezahipotético+neutro. Essa ordem parece ser rígida e pode ser observada nos dados abaixo:

(21) E-mago-ru-mëde

3pl-conversar-incereteza-hipotético+neutro

'Eles parecem conversar'

(22) E-mago-ru-nire

3pl-conversar-incerteza-estativo

'Eles parecem estar conversando'

Uma das características dos clíticos é uma certa rigidez no que se refere à ordem em se colocam uns em relação aos outros. No caso do Boróro, essa característica parece ser evidenciada nos dados acima e no que afirma Crowell em seu trabalho.

Esse seria, então, não um argumento propriamente dito em favor da análise desses elementos como clíticos - já que os sufixos também apresentam uma ordem fixa uns em relação aos outros no interior das palavras - , mas uma característica dos chamados clíticos, evidenciada nos dados do Boróro.

\section{CONSIDERAÇÕES FINAIS}

Este trabalho teve a intenção de iniciar uma discussão sobre a análise dos morfemas que expressam tempo, aspecto e modo do Boróro como sufixos, proposta por Crowell (1979).

Neste estudo preliminar, apresentamos algumas evidências que questionam essa análise e levam a uma outra perspectiva, que considera esses elementos não como sufixos, mas como clíticos.

\footnotetext{
${ }^{12} \mathbf{A k i}$, na grafia atual.
} 
Os principais argumentos apresentados no trabalho em favor dessa análise foram (i) o fato de esses elementos não selecionarem de maneira rígida as categorias gramaticais às quais se ligam, podendo estar ligados a nomes, verbos, pronomes e adjetivos, por exemplo e (ii) o fato de que a relação que tais elementos estabelecem com as raízes a que se ligam ser de natureza mais sintática que morfológica.

Somadas a esses argumentos, outras características comuns aos clíticos foram evidenciadas nos dados, como, por exemplo, uma certa rigidez quanto ao ordenamento desses elementos, uns em relação aos outros e o fato de nunca poderem aparecer isoladamente.

Essa análise ainda trouxe conseqüências para outros pontos de análise e descrição da língua Boróro. Uma delas foi bastante discutida neste trabalho, que é o fato de estarmos considerando a possibilidade de os morfemas pessoais dessa língua, antes analisados como prefixos, poderem ser analisados como pronomes livres, ocorrendo independentemente das raízes verbais.

Outra conseqüência é algo ainda não explorado neste trabalho que é a possibilidade de o Boróro poder ser analisado como uma língua de tópico, ou, até mesmo, uma língua voltada para o discurso.

Segundo Negrão (1999: 1), "por língua voltada para o discurso entende-se uma língua que privilegia marcar na sintaxe aberta $^{13}$ a função informacional dos constituintes de sua sentença, ou seja, funções como tópico do discurso ou foco, ou ainda o escopo de sintagmas quantificados."

Essa possibilidade de análise deve-se ao fato de, nessa língua, serem muito comuns construções como (22), abaixo, em que se constata a presença de um sujeito gramatical explícito e 'ele' precedido de um elemento a ele co-referente — ime 'homens' — que poderia, numa primeira análise, ser identificado como o tópico discursivo:

(23) Ime e-kujagu-medi-ka-re

Homem 3pl-vermelho-hipotético-negação-neutro

'O homem não ficará vermelho'

Literalmente, a sentença em (22) poderia ser traduzida como 'O homem, ele não ficará vermelho', em que o sintagma 'o homem' funciona como tópico discursivo e o pronome 'ele' funciona como sujeito da oração. De acordo com essa perspectiva, a glosa poderia ser refeita da seguinte maneira:

(24) Ime, e $\quad$ kujagu $=$ medi $=\mathrm{ka}=\mathrm{re}^{14}$

Homem ele vermelho-hipotético-negação-neutro

'O homem não ficará vermelho'

${ }^{13}$ "No jargão da Teoria Gerativa, sintaxe aberta significa, ou o nível representação conhecidos como Estrutura-S no modelo de Princípios e Parâmetros, ou na etapa da derivação antes da operação Spell-out, que envia as informações para o componente fonológico, na visão minimalista desse modelo de gramática" (cf.: Negão, 1999: 1, rodapé)

${ }^{14}$ Para fins de formalização, estaremos utilizando o hífen (-) para separar morfemas de uma mesma palavra e o sinal de igualdade (=), para separar palavras de clíticos. 
Contudo, essa é uma possibilidade que deixaremos de lado, neste trabalho, mas que deverá ser retomada em trabalhos posteriores.

Outra discussão importante a ser investigada futuramente é sobre a categorização dos morfemas de tempo, aspecto e modo do Boróro. São uma subclasse de verbos ou constituem uma classe independente? Se não são verbos, a que classe pertencem? Se essa hipótese for comprovada, pode-se, então, propor que tempo, aspecto e modo não são propriedades intrínsecas do verbo, como usualmente se propõe, mas uma propriedade da proposição?

São todas questões interessantes que nos encaminham para um longo trabalho de pesquisa acerca da morfossintaxe da língua Boróro.

\section{REFERÊNCIASBIBLIOGRÁFICAS}

ALBISETTI, César \& VENTURELLI, (1962) Ângelo Jaime. Enciclopédia Boróro. Campo Grande, Museu Regional Dom Bosco.

ANDERSON, Stephen R. (1985) "Inflectional morphology". In: SHOPEN, Timothy (org). Language typology and syntatic description (volume 1). Cambridge University Press.

COLBACCHINI, Antonio \& ALBISETTI, César. (1942). Os Boróros orientais orarimogodogue do planalto oriental de Mato Grosso. São Paulo, Brasiliana.

CROWELL, Thomas H. (1977). "The Phonology of Boróro verb, posposition and noum paradigms". In: Arquivos de Anatomia e Antropologia 159-178.

(1979) A Grammar of Bororo. Cornell University, tese de doutorado, ms.

HUESTIS, George. (1963). "Bororo clause structure" In: IJAL 29: 3, 230-238.

NEGRÃO, Esmeralda Vailati. (1999) O Português Brasileiro: Uma língua voltada para o discurso. Tese de livre docência, São Paulo, USP.

RODRIGUES, Aryon D. (1962). (Comparação das línguas Umutína e Boróro) in SCHULTZ, Harald. Informações etnográficas sobre os Umutína, In: Revista do Museu Paulista, s/n, vol. 13, São Paulo, pp. 99-108.

.(1986) Línguas brasileiras: para o conhecimento das línguas indígenas. São Paulo: Loyola. .(2000) "Flexão relacional no tronco lingüístico Macro-Jê" In: SOARES, Maria Elias (org) Boletim da ABRALIN, n 25, pp. 219-231.

RONDON, Cândido Mariano da Silva \& FARIA, João Barbosa de (1948), Esboço gramatical e vocabulário da língua dos índios Boróro. Rio de Janeiro, Conselho Nacional de Proteção oas Índios.

SCHACHTER, Paul. (1985). "Part-of-speech systems" In: SHOPEN, Timothy (org.). Language typology and syntatic description (volume 1). Cambridge University Press.

SHOPEN, Timothy (editor). Language typology and syntatic description (volume 1). Cambridge University Press.

ZWICKY, Arnold \& PULLUM, Geoffrey. (1993). "Clitization vs. Inflection: English n’t”. Language 59: 502-513.

ZWICKY, Arnold. (1977) “On Clitics”. Bloomington, Indiana University Linguistcs Club. (1985) Clitics and particles. Language 61: 2. 